\title{
PENENTUAN HARI - HARI BESAR ISLAM PADA TAHUN 1450 H DENGAN MENGGUNAKAN KEKONGRUENAN ZELLER
}

\author{
Ade Novia Rahma ${ }^{1}$, \\ ${ }^{1}$ Jurusan Matematika, Fakultas Sains dan Teknologi, UIN Sultan Syarif Kasim Riau \\ adenoviarahma_mufti@yahoo.co.id ${ }^{1}$
}

\begin{abstract}
Zeller's congruence system can be used to determine the days of a calendar system. Determination of Islamic holy days can be completed by using the expansion of Zeller's congruence. The basic theories used in calculating the determination of one day are modulo arithmetic and floor functions. The Hijriyah calendar system is one of the broadest dating systems in Indonesia and other Muslim countries used to determine the commemoration of Islamic holy days. Based on the results of literature studies obtained 10 Islamic days in 1450 Hijriyah.
\end{abstract}

Keywords: Hijriah, Zeller's congruence, Modulo,

\begin{abstract}
Abstrak
Sistem kekongruenan Zeller dapat digunakan untuk menentukan hari-hari dari suatu sistem penanggalan. Penentuan hari-hari besar Islam dapat diselesaikan dengan menggunakan perluasan kekongruenan Zeller. Teori-teori dasar yang digunakan dalam perhitungan penentuan suatu hari adalah aritmatika modulo dan fungsi floor. Sistem penanggalan Hijriyah merupakan salah satu sistem penanggalan yang luas pemakaiannya di Indonesia dan negara muslim lainnya yang digunakan untuk menentukan peringatan hari-hari besar Islam. Berdsarkan hasil studi pustaka diperoleh 10 harihari besar Islam pada tahun 1450 Hijriyah.
\end{abstract}

Kata kunci : Hijriyah, Kekongruenan Zeller, sistem modulo 
Jurnal Lebesgue : Jurnal Ilmiah Pendidikan Matematika, Matematika dan Statistika

Ade Novia Rahma

Volume 2, No. 2, Agustus 2021 hal.233-243

DOI Artikel : 10.46306/lb.v2i2.79

\section{PENDAHULUAN}

Kalender Islam atau disebut kalender Hijriyah merupakan kalender yang perhitungannya didasarkan pada peredaran Bulan mengelilingi Bumi. Kalender Hijriyah tidak pernah terlepas dengan problematika penetapan awal bulan terutama berkaitan bulan-bulan ibadah umat Islam. Pada awalnya penetapan awal bulan di Tahun Hijriyah ditentukan dengan melihat hilal (bulan muda). Setelah berkembangnya ilmu pengetahuan, ada sebagian umat Islam mulai menggunakan hisab sebagi sarana menentukan awal bulan pada tahun Hijriyah.

Penelitian terdahulu yang berkaitan dengan penanggalan hijriah yaitu Hambali, Slamet membahas tentang Astronomi Islam dan Teori Heliocentris Nicolaus Copernicus, selanjutnya penelitian yang dilakukan oleh Adib Rofiuddin, Ahmad membahas tentang Penentuan Hari dalam Sistem Kalender Hijriah.

Penentuan hari pada kalender Hijriyah dengan menggunakan sistem hisab (hilal) dapat digantikan dengan menggunakan sistem perkongruenan Zeller. Dengan memperluas sistem perkongruenan tersebut juga dapat menentukan hari-hari besar Islam. Maka dari itu pada penelitian ini dibahas mengenai penentuan 10 hari-hari besar Islam pada tahun 1450 Hijriyah menggunakan perkuasan kekongruenan Zeller. Penelitian ini lanjutan penelitian sebelumnya yang telah dilakukan oleh David Hoesen dengan judul "Penentuan Hari pada Berbagai Sistem Penanggalan menggunakan Kekongruenan Zeller", nah pada tulisan ini akan dilanjutkan dengan judul "Penentuan Hari - Hari Besar Islam pada Tahun 1450 H dengan Menggunakan Kekongruenan Zeller.

\section{METODE PENELITIAN}

Adapun metode yang digunakan pada penelitian ini adalah tinjauan pustaka dengan teori-teori pendukung yaitu konsep aritmatika, kekongruenan zeller dan kalender hijriah.

\section{Definisi 1}

Misalkan $a$ adalah bilangan bulat dan $m$ adalah bilangan bulat $>0$. Operasi $a$ mod $m$ (dibaca " $a$ mod $m$ “) memberikan sisa positif jika $a$ dibagi $m$. dengan kata lain, $a$ mod $m=r$ sedemikian $a=m q+r$, dengan $0 \leq r<m$.

Tabel 1. Sistem Modulo 7

\begin{tabular}{|c|c|c|c|c|c|c|c|}
\hline+ & 0 & 1 & 2 & 3 & 4 & 5 & 6 \\
\hline 0 & 0 & 1 & 2 & 3 & 4 & 5 & 6 \\
\hline 1 & 1 & 2 & 3 & 4 & 5 & 6 & 0 \\
\hline 2 & 2 & 3 & 4 & 5 & 6 & 0 & 1 \\
\hline 3 & 3 & 4 & 5 & 6 & 0 & 1 & 2 \\
\hline 4 & 4 & 5 & 6 & 0 & 1 & 2 & 3 \\
\hline
\end{tabular}


Volume 2, No. 2, Agustus 2021 hal.233-243

DOI Artikel : 10.46306/lb.v2i2.79

\begin{tabular}{|l|l|l|l|l|l|l|l|}
\hline 5 & 5 & 6 & 0 & 1 & 2 & 3 & 4 \\
\hline 6 & 6 & 0 & 1 & 2 & 3 & 4 & 5 \\
\hline
\end{tabular}

Penentuan hari atau minggu dalam Kalender Hijriyah dapat menggunakan modulo 7 karena banyaknya hari dalam satu minggu adalah 7 . Hari dalam seminggu dapat dicatat dengan bilangan 0,1,2,3,4,5,6 dengan aturan:
1) Sabtu
$=0$
2) Minggu
$=1$
3) Senin
$=2$
4) Selasa
$=3$
5) Rabu
$=4$
6) Kamis
$=5$
7) Jum'at
$=6$

\section{Fungsi Floor}

Fungsi floor dari $x$ ditulis $\lfloor x\rfloor$ memetakan suatu bilangan real ke bilangan bulat sebelumnya. Secara lebih detail, floor menyatakan bilangan bulat terbesar yang kurang dari atau sama dengan $x$.

Beberapa contoh nilai dari fungsi floor adalah sebagai berikut

$$
\begin{array}{ll}
\lfloor 2.25\rfloor=2 & \lfloor-2.25\rfloor=-3 \\
\left\lfloor\frac{21}{5}\right\rfloor=4 & \left\lfloor-\frac{21}{5}\right\rfloor=-4
\end{array}
$$

Beberapa sifat fungsi floor adalah sebagai berikut

1. Jika $n$ adalah bilangan bulat, maka $\lfloor x+n\rfloor=\lfloor x\rfloor+n$

2. $\lfloor\lfloor x\rfloor\rfloor=\lfloor x\rfloor($ sifat idempoten $)$.

3. Jika $n$ adalah bilangan positif, maka $\left\lfloor\frac{x+m}{n}\right\rfloor=\left\lfloor\frac{\lfloor x\rfloor+m}{n}\right\rfloor$

4. Jika $m$ dan $n$ adalah bilangan bulat positif maka $\left\lfloor\frac{x / m}{n}\right\rfloor=\left\lfloor\frac{x}{m n}\right\rfloor$

\section{Sistem Perkalenderan Hijriyah}

Kalender Hijriyah atau kalender Islam merupakan penentuan tanggal atau bulan yang berkaitan dengan ibadah dan hari-hari penting lain umat Islam. Penamaan bulan-bulan dan jumah hari dalam kalender Hijriyah ini adalah sebagai berikut.

Tabel 2. Nama Bulan dan Jumlah Hari Kalender Hijriyah

\begin{tabular}{|c|c|c|}
\hline No & Bulan & Jumlah hari \\
\hline 1. & Muharram & 30 \\
\hline
\end{tabular}




\begin{tabular}{|c|c|c|}
\hline 2. & Safar & 29 \\
\hline 3. & Rabi'ul Awal & 30 \\
\hline 4. & Rabi'ul Akhir & 29 \\
\hline 5. & Jumadil Awal & 30 \\
\hline 6. & Jumadil Akhir & 29 \\
\hline 7. & Rajab & 30 \\
\hline 8. & Sya'ban & 29 \\
\hline 9. & Ramadhan & 30 \\
\hline 10. & Syawal & 30 \\
\hline 11. & Dzulkaidah & 29 (kabisat: 30 ) \\
\hline 12. & Dzulhijah & 29 \\
\hline
\end{tabular}

\section{Kekongruenan Zeller}

\subsection{Beberapa persamaan kekongruenan Zeller}

Persamaan ini ditemukan oleh Julius Christian Johannes Zeller, seorang pendeta dan matematikawan berkebangsaan Jerman. Kekongruenan Zeller dimaksudkan untuk diterapkan pada kalender Gregorian dan Julian.

1) Kalender Gregorian

$h=\left(d+\left\lfloor\frac{13(m+1)}{5}\right\rfloor+y+\left\lfloor\frac{y}{4}\right\rfloor+\left\lfloor\frac{c}{4}\right\rfloor-2 c\right) \bmod 7$

2) Kalender Julian

$h=\left(d+\left\lfloor\frac{13(m+1)}{5}\right\rfloor+y+\left\lfloor\frac{y}{4}\right\rfloor+-c+5\right) \bmod 7$

Keterangan:

- $\mathrm{h}$ adalah hari dalam satu minggu $($ Sabtu $=0$, Minggu $=1, \ldots$, Jum'at $=6$ )

- $\mathrm{d}$ adalah tanggal yang akan dicari harinya

- $\mathrm{m}$ adalah bulan dari tanggal yang ingin dicari harinya $(3=$ Maret, $4=$ April, $\ldots, 13=$ Januari, $14=$ Februari)

- y adalah tahun pada abad yang dimaksud ( tahun mod 100)

- $c$ adalah "abad” (100 tahun) sehingga tahun 2011 bukan abad ke-21 tetapi abad ke-20.

Catatan : 
Jurnal Lebesgue : Jurnal Ilmiah Pendidikan Matematika, Matematika dan Statistika

Ade Novia Rahma

Volume 2, No. 2, Agustus 2021 hal.233-243

DOI Artikel : 10.46306/lb.v2i2.79

Dalam persamaan-persamaan ini, Januari dan Februari dihitung sebagai bulan ke-13 dan ke-14 dari tahun sebelumnya. Contoh Januari 2011 dimasukkan ke dalam persamaan ini sebagi bulan ke - 13 tahun 2010.

\subsection{Perluasan Kekongruenan Zeller pada Kalender Hijriyah}

Dengan menggunakan persamaan-persamaan di atas, sangat memungkinkan untuk memperluas kekongruenan Zeller ini untuk memperkirakan hari dari suatu tanggal pada kalender Hijriyah. Kita mulai setahap demi setahap. Kita misalkan variabel yang ingin dicari hasil baginya oleh 7 adalah $a$.

Pertama, $a$ bertambah 1 ketika tanggal $d$ bertamah 1, sehingga langkah pertama adalah membangun persamaan berikut.

$a=d$

Selanjutnya kita lihat pengaruh pertambahan tahun $Y$ terhadap mundurnya hari tanpa memperhatikan tahun kabisat. Perlu diingat bahwa tahun yang digunakan ini adalah tahun apa adanya bukan tahun dalam satu abad (1433 H berarti $Y=1433$ bukan 33). Jumlah hari dalam satu tahun biasa adalah 354 hari. Karena $354 \bmod 7=4$, bertambahnya tahun $Y$ mengakibatkan mundur 4 hari.

$a=d+4 Y$

Sekarang kita lihat pengaruh tahun kabisat terhadap mundurnya hari. Setiap 30 tahun terdapat 11 hari kabisat, sehingga hari mundur 11 hari.

$a=d+4 Y+11\left\lfloor\frac{Y}{30}\right\rfloor$

Sisa pembagian tahun $Y$ dengan 30 menentukan sudah berapa tahun kabisat yang terlewati dalam jaangka waktu 30 tahunan itu. Karena perhitungan untuk menentukan tahun kabisat cukup rumit, dapat dinyatakan dalam nilai $k_{Y}$ yang diberikan dalam tabel berikut.

Tabel 3. Nilai ky

\begin{tabular}{|c|c|}
\hline Nilai $r=Y \bmod 30$ & Nilai $k_{Y}$ \\
\hline $\mathrm{r} \leq 2$ & 0 \\
\hline $2<\mathrm{r} \leq 5$ & 1 \\
\hline $5<r \leq 7$ & 2 \\
\hline $7<\mathrm{r} \leq 10$ & 3 \\
\hline $10<\mathrm{r} \leq 13$ & 4 \\
\hline $13<\mathrm{r} \leq 15$ (Basis-15) & \multirow[t]{2}{*}{5} \\
\hline $13<\mathrm{r} \leq 16$ (Basis-16) & \\
\hline $15<\mathrm{r} \leq 18$ (Basis-15) & \multirow[t]{2}{*}{6} \\
\hline $16<\mathrm{r} \leq 18$ (Basis-16) & \\
\hline
\end{tabular}




\begin{tabular}{|c|c|}
\hline $18<\mathrm{r} \leq 21$ & 7 \\
\hline $21<\mathrm{r} \leq 24$ & 8 \\
\hline $24<\mathrm{r} \leq 26$ & 9 \\
\hline $26<\mathrm{r} \leq 29$ & 10 \\
\hline
\end{tabular}

Dengan nilai $k_{Y}$ tersebut, persamaan menjadi

$a=d+4 Y+11\left\lfloor\frac{Y}{30}\right\rfloor+k_{Y}$

Untuk perhitungan bulan, diketahui bahwa kelebihan hari berulang setiap 2 bulan. Setiap dua bulan itu, mundurnya hari adalah 3 hari. Karena yang akan dicari adalah nilai $a$ mod 7, maka kita gunakan sifat (2) fungsi floor pada suku $11\left\lfloor\frac{Y}{30}\right\rfloor$ sehingga berubah menjadi :

$a=d+\left\lfloor\frac{3 m}{2}\right\rfloor+4 Y+4\left\lfloor\frac{Y}{30}\right\rfloor+k_{Y}$

Dengan penjabaran di atas dapat disimpulkan rumus untuk menentukan hari dalam kalender Hijriyah, yaitu :

$h=\left(d+\left\lfloor\frac{3 m}{2}\right\rfloor+4 Y+4\left\lfloor\frac{Y}{30}\right\rfloor+\mathrm{k}_{\mathrm{Y}}\right) \bmod 7$

keterangan:

- $h$ adalah hari dalam satu minggu

- $d$ adalah tanggal yang akan dicari harinya

- $m$ adalah bulan yang ingin dicari harinya ( 1 = Muharram, $2=$ Safar, $\ldots, 12=$ Dzulhijah)

- $y$ adalah tahun dari tanggal yang bersangkutan

- $k_{y}$ adalah nilai yang menyatakan jumlah tahun kabisat

\section{HASIL DAN PEMBAHASAN}

Penelitian berguna untuk menentukan 10 hari - hari besar Islam pada tahun 1450 Hijriyah. Adapun langkahnya terlebih dahulu diketahui beberapa hal yang dicari sebelumnya pada tabel berikut ini.

Tabel 4. Penentuan Hari-Hari Besar Islam

\begin{tabular}{|c|c|c|c|c|c|}
\hline $\begin{array}{c}\text { Tanggal yang } \\
\text { akan } \\
\text { dicari(d) }\end{array}$ & $\begin{array}{c}\text { Bulan yang } \\
\text { akan dicari } \\
\text { harinya(m) }\end{array}$ & $\begin{array}{c}\text { Tahun dari } \\
\text { tanggal yang } \\
\text { bersangkutan(Y }(\mathrm{Y}\end{array}$ & $\begin{array}{c}\text { Nilai r } \\
r=\bmod \\
30\end{array}$ & $\begin{array}{c}\text { Nilai yang } \\
\text { menyatakan } \\
\text { jumlah tahun } \\
\text { kabisat yang telah } \\
\text { dilewati dalam }\end{array}$ \\
\hline
\end{tabular}




\begin{tabular}{|c|c|c|c|c|c|}
\hline & & & & & $\begin{array}{c}\text { jangka waktu tiga } \\
\text { puluh tahunan(ky) }\end{array}$ \\
& & & & & \\
\hline 1. & 1 & Muharram & 1450 & 10 & 3 \\
\hline 2. & 10 & Muharram & 1450 & 10 & 3 \\
\hline 3. & 12 & Rabi'ul Awal & 1450 & 10 & 3 \\
\hline 4. & 27 & Rajab & 1450 & 10 & 3 \\
\hline 5. & 1 & Ramadhan & 1450 & 10 & 3 \\
\hline 6. & 17 & Ramadhan & 1450 & 10 & 3 \\
\hline 7. & 1 & Syawal & 1450 & 10 & 3 \\
\hline 8. & 10 & Dzulhijjah & 1450 & 10 & 3 \\
\hline 9. & 11 & Dzulhijjah & 1450 & 10 & 3 \\
\hline 10. & 13 & Dzulhijjah & 1450 & 10 & \\
\hline
\end{tabular}

Dari table diatas sudah diketahui tanggal yang akan dicari (d), Bulan yang akan dicari harinya(m), Tahun dari tanggal yang bersangkutan(Y), kemudian $r$ serta Nilai yang menyatakan jumlah tahun kabisat yang telah dilewati dalam jangka waktu tiga puluh tahunan( $\left.\mathrm{k}_{\mathrm{Y}}\right)$. langkah berikutnya melakukan pencarian menggunakan rumus yang didapatkan pada persamaan (8),

\section{1) Tahun Baru (1 Muharram $1450 \mathrm{H})$}

$$
\begin{aligned}
\mathrm{d}= & =1, \mathrm{~m}=1, \mathrm{Y}=1450, \\
\mathrm{r}= & =1450 \bmod 30 \\
\mathrm{r}= & 10, \operatorname{maka} k_{Y}=3 \\
h & =\left(1+\left[\frac{3(1)}{2}\right]+4(1450)+4\left[\frac{1450}{30}\right]+3\right) \bmod 7 \\
& =5997 \bmod 7 \\
& =5 \text { (kamis) }
\end{aligned}
$$

Jadi, tahun baru islam pada tahun 1450 hijriah jatuh pada hari kamis

\section{2) Puasa ‘Assyura (10 Muharram 1450 H)}

$\mathrm{d}=10, \mathrm{~m}=1, \mathrm{Y}=1450$,

$\mathrm{r}=1450 \bmod 30$

$\mathrm{r}=10$, maka $k_{Y}=3$

$$
\begin{aligned}
h & =\left(10+\left[\frac{3(1)}{2}\right]+4(1450)+4\left[\frac{1450}{30}\right]+3\right) \bmod 7 \\
& =6006 \bmod 7 \\
& =0(\text { Sabtu })
\end{aligned}
$$

Jadi, Puasa 'Assyura pada tahun 1450 hijriah jatuh pada hari sabtu 


\section{3) Maulid Nabi Muhammad SAW (12 Rabi’ul Awal 1450 H)}

$\mathrm{d}=12, \mathrm{~m}=3, \mathrm{Y}=1450$,

$\mathrm{r}=1450 \bmod 30$

$\mathrm{r}=10$, maka $k_{Y}=3$

$$
\begin{aligned}
h & =\left(12+\left[\frac{3(3)}{2}\right]+4(1450)+4\left[\frac{1450}{30}\right]+3\right) \bmod 7 \\
& =6611 \bmod 7 \\
& =5 \text { (Kamis) }
\end{aligned}
$$

Jadi, Maulid Nabi Muhammad SAW pada tahun 1450 hijriah jatuh pada hari kamis

4) Isra' mi'raj (27 Rajab $1450 \mathrm{H})$

$\mathrm{d}=27, \mathrm{~m}=7, \mathrm{Y}=1450$,

$\mathrm{r}=1450 \bmod 30$

$\mathrm{r}=10$, maka $k_{Y}=3$

$h=\left(27+\left[\frac{3(7)}{2}\right]+4(1450)+4\left[\frac{1450}{30}\right]+3\right) \bmod 7$

$=6032 \bmod 7$

$=5$ (Kamis)

Jadi, Isra' mi'raj pada tahun 1450 hijriah jatuh pada hari kamis

\section{5) Awal Ramadhan (1 Ramadhan $1450 \mathrm{H}$ )}

$\mathrm{d}=1, \mathrm{~m}=9, \mathrm{Y}=1450$,

$\mathrm{r}=1450 \bmod 30$

$\mathrm{r}=10$, maka $k_{Y}=3$

$$
\begin{aligned}
h & =\left(1+\left[\frac{3(9)}{2}\right]+4(1450)+4\left[\frac{1450}{30}\right]+3\right) \bmod 7 \\
& =6009 \bmod 7 \\
& =3(\text { Selasa })
\end{aligned}
$$

Jadi, Awal Ramadhan pada tahun 1450 hijriah jatuh pada hari selasa

6) Nuzulul Qur'an (17 Ramadhan 1450 H)

$\mathrm{d}=17, \mathrm{~m}=9, \mathrm{Y}=1450$,

$\mathrm{r}=1450 \bmod 30$

$\mathrm{r}=10$, maka $k_{Y}=3$

$h=\left(17+\left[\frac{3(9)}{2}\right]+4(1450)+4\left[\frac{1450}{30}\right]+3\right) \bmod 7$

$=6025 \bmod 7$ 


$$
=5 \text { (Kamis) }
$$

Jadi, Nuzulul Qur'an pada tahun 1450 hijriah jatuh pada hari kamis

\section{7) Hari Raya Idul Fitri (1 Syawal 1450 H)}

$\mathrm{d}=1, \mathrm{~m}=10, \mathrm{Y}=1450$,

$\mathrm{r}=1450 \bmod 30$

$\mathrm{r}=10$, maka $k_{Y}=3$

$$
\begin{aligned}
h & =\left(1+\left[\frac{3(10)}{2}\right]+4(1450)+4\left[\frac{1450}{30}\right]+3\right) \bmod 7 \\
& =6011 \bmod 7 \\
& =5 \text { (Kamis) }
\end{aligned}
$$

Jadi, Hari Raya Idul Fitri pada tahun 1450 hijriah jatuh pada hari kamis

8) Hari Raya Idul Adha (10 Dzulhijjah 1450 H)

$\mathrm{d}=10, \mathrm{~m}=12, \mathrm{Y}=1450$,

$\mathrm{r}=1450 \bmod 30$

$\mathrm{r}=10$, maka $k_{Y}=3$

$$
\begin{aligned}
h & =\left(10+\left[\frac{3(12)}{2}\right]+4(1450)+4\left[\frac{1450}{30}\right]+3\right) \bmod 7 \\
& =6023 \bmod 7 \\
& =3 \text { (Selasa) }
\end{aligned}
$$

Jadi, Hari Raya Idul Adha pada tahun 1450 hijriah jatuh pada hari selasa

9) Hari Tasyrik (11 Dzulhijjah $1450 \mathrm{H}$ )

$\mathrm{d}=11, \mathrm{~m}=12, \mathrm{Y}=1450$,

$\mathrm{r}=1450 \bmod 30$

$\mathrm{r}=10$, maka $k_{Y}=3$

$$
\begin{aligned}
h & =\left(11+\left[\frac{3(12)}{2}\right]+4(1450)+4\left[\frac{1450}{30}\right]+3\right) \bmod 7 \\
& =6024 \bmod 7 \\
& =4(\text { Rabu })
\end{aligned}
$$

Jadi, Hari Tasyrik pada tahun 1450 hijriah jatuh pada hari rabu

10) Hari Tasyrik (13 Dzulhijjah 1450 H)

$\mathrm{d}=13, \mathrm{~m}=12, \mathrm{Y}=1450$,

$\mathrm{r}=1450 \bmod 30$

$\mathrm{r}=10$, maka $k_{Y}=3$ 


$$
\begin{aligned}
h & =\left(13+\left[\frac{3(12)}{2}\right]+4(1450)+4\left[\frac{1450}{30}\right]+3\right) \bmod 7 \\
& =6026 \bmod 7 \\
& =6(\text { Jum'at })
\end{aligned}
$$

Jadi, Hari Tasyrik pada tahun 1450 hijriah jatuh pada hari jum'at

Berdasarkan pencarian di atas, hasil-hasil tersebut juga dapat disajikan dalam tabel sebagai berikut.

Tabel 5. Hasil Penentuan Hari-Hari Besar Islam

\begin{tabular}{|c|c|c|c|c|}
\hline No & Peringatan & Tanggal & Sisa & Hari \\
\hline 1. & Tahun Baru & 1 Muharram 1450 & 5 & Kamis \\
\hline 2. & Puasa 'Asyura & 10 Muharram 1450 & 0 & Sabtu \\
\hline 3. & Mulid Nabi SAW & 12 Rabi'ul Awal & 5 & Kamis \\
\hline 4. & Isra' Mi'raj & 27 Rajab 1450 & 5 & Kamis \\
\hline 5. & Awal Ramadhan & 1 Ramadhan 1450 & 3 & Selasa \\
\hline 6. & Nuzulul Qur'an & 17 Ramadhan 1450 & 5 & Kamis \\
\hline 7. & $\begin{array}{c}\text { Hari Raya 'Idul } \\
\text { Fitri }\end{array}$ & 1 Syawal 1450 & 5 & Kamis \\
\hline 8. & $\begin{array}{c}\text { Hari Raya 'Idul } \\
\text { Adha }\end{array}$ & 10 Dzuhijjah 1450 & 2 & Senin \\
\hline 9. & Hari Tasyrik & 11 Dzulhijjah 1450 & 4 & Rabu \\
\hline 10 & Hari Tasyrik & 13 Dzulhijjah 1450 & 6 & Jum'at \\
\hline
\end{tabular}

Dari langkah langkah dengan menggunakan persamaan (8) tentunya kita sebagai matematikawan sangat mudah menentukan hari-hari besar Islam dengan menggunakan perluasan kekongruenan Zeller. Dari Tabel 5 terlihat bahwa hari-hari besar Islam banyak di hari kamis .

\section{KESIMPULAN}

Prinsip dasar perhitungan kekongruenan Zeller adalah menghitung perubahan jangka waktu tertentu baik perubahan tanggal (hari), bulan, tahun, empat thunan (kabisat), abad, empat ratus tahunan, maupun jangka waktu lainnya.

Dengan prinsip dasar tersebut, Kekongruenan Zeller dapat diperluas untuk memperkirakan hari dari suatu tanggal pada penanggalan Hijriyah. Perubahan jangka waktu yang diperhitungkan dalam penanggalan ini adalah perubahan tanggal (hari), bulan, tahun, tiga puluh tahunan, dan tahun kabisat yang jangka waktunya tidak pasti.

Dalam tulisan ini, dapat ditarik kesimpulan bahwa dengan menggunakan perluasan Kekongruenan Zeller bahwa menentukan 10 Hari-Hari Besar Islam Tahun1450 H terbukti dengan mencocokkannya di kalender. 


\section{DAFTAR PUSTAKA}

Adib Rofiuddin, Ahmad. Penentuan. Hari dalam Sistem Kalender Hijriah, AlAhkam, vol. 26, 2016.

Bashori, Muh. Hadi. Penanggalan Islam, Jakarta: PT. Elex Media Komputindo, 2013.

Devin Hoesen.2011.Penentuan Hari pada Berbagai Sistem Penanggalan Menggunakan Kekongruenan Zeller.Senin, 9 Desember 2019.

"Fungsi Floor." Wikipedia, Ensiklopedia Bebas. Senin, 16 Desember 2019. < https://www.m4th-lab.net/2018/02/fungsi-floor-dan-fungsi-ceiling.html >.

Hambali, Slamet. Astronomi Islam dan Teori Heliocentris Nicolaus Copernicus, Al-Ahkam, vol. 23, 2013.

Izzuddin, Ahmad. Sistem Penanggalan, Semarang: CV. Karya Abadi Jaya, 2015.

Sukirman, H. Pengantar Teori Bilangan. Yogyakarta, 2006.

"Zeller's Congruence." Wikipedia, the Free Encyclopedia. Senin, 16 Desember 2019. <en.wikipedia.org/wiki/Zeller's_congruence>.

"Kalender Islam." Wikipedia, Ensiklopedia Bebas. Senin, 16 Desember 2019. < en.wikipedia.org/wiki/Islamic_calendar >. 